\title{
Programas de teatro: objeto e fonte
}

\section{Theatre programs: object and source}

\author{
Walter Lima Torres Neto
}

Walter Lima Torres Neto

Professor do Departamento de Letras Estrangeiras e Modernas e do PPG em Letras da Universidade Federal do Paraná (UFPR).

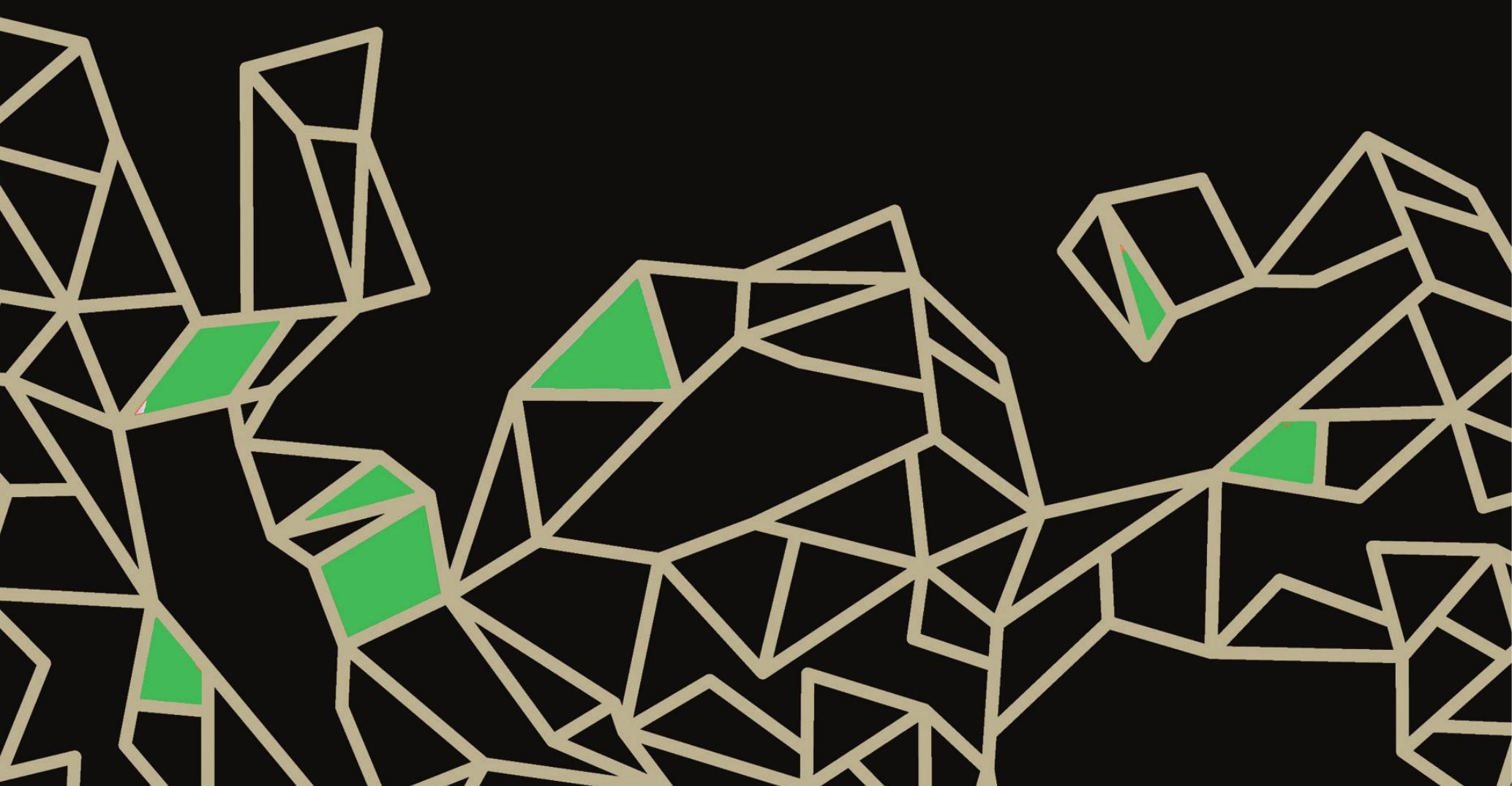




\section{Resumo}

Neste artigo, procuro relatar a minha experiência de pesquisa com os programas de espetáculos teatrais. Retomo alguns pontos da investigação sobre os projetos editoriais dos programas de teatros em diferentes centros de documentação. Apesar de rever algumas conclusões parciais já divulgadas em artigos anteriores, acrescento aqui uma reflexão sobre o programa de espetáculo enquanto objeto integrante de coleções "efêmera teatral," e chamo atenção para a aproximação de nossos acervos de artes cênicas, não só de programas, com as humanidades digitais.

Palavras-chave: Programa de teatro, Jornal-programa, Programa da peça.

\section{Abstract}

In this article, I try to report my research experience with theater programs. I resume some research points about the editorial projects of theater programs in different documentation centers. Although I review some partial conclusions already published in previous articles, I add here a reflection about the program as an integrating object of ephemera theatrical collections, and draw an approximation of our collections of performing arts, not only of programs, to the digital humanities.

Keywords: Theatre program, Theatre-journal, Playbill.

- RAPAZES, também eu fui rapaz, disse o mestre, o Pitada, um velho mestre de meninos da Gamboa, no ano de 1850; fui rapaz, mas rapaz de muito juízo, muito juízo... Entenderam?

- Sim, senhor.

- Não entrei no mundo como um desmiolado, dando por paus e por pedras, mas com um programa na mão... Sabem o que é um programa?

MACHADO DE ASSIS. O programa.

O evento já é entregue maquiado ao leitor, ao ouvinte, ao telespectador, e é também por isso que se produzem no mundo de hoje, simultaneamente, fábulas e mitos.

MILTON SANTOS. Por uma globalização. 


\section{O itinerário de uma pesquisa em movimento}

A escolha por trabalhar com os programas de teatro se deu em consequência da minha trajetória de vida acadêmica. $O$ fato de eu ter me transferido de um curso de artes cênicas (Direção teatral, na Universidade Federal do Rio de Janeiro - UFRJ) para um curso de letras, mesmo continuando a trabaIhar com teatro, fez com que eu revisse minhas escolhas acerca de um objeto de pesquisa, no âmbito agora dos estudos da pós-graduação em letras.

No curso de direção teatral, pesquisei as origens do trabalho criativo e os procedimentos cênicos do ensaiador dramático de matriz portuguesa. O trabalho intelectual e o esforço criativo desse agente da cena oitocentista precederam, no meu ponto de vista, o exercício da moderna função de diretor teatral, que se consolidou entre nós, sobretudo depois da presença dos diretores italianos no Teatro Brasileiro de Comédia (TBC). Todavia não dei como "superadas" as atividades do ensaiador dramático: simplesmente elas foram convivendo com as novas práticas do moderno diretor teatral, até o desparecimento inclusive da designação "ensaiador". Ficou claro para mim, naquela ocasião, que o ensaiador dramático era o agenciador sobre o palco da reprodutibilidade de gêneros e formas teatrais, enquanto o moderno diretor teatral se afirmava por meio de obras cênicas nas quais se buscava maior singularidade por meio de uma criação demiúrgica. Isso não pressupõe uma hierarquia entre ambos, mas sim a explicitação de comportamentos criativos distintos. Ao término de uma pesquisa sobre a natureza do trabalho teatral entre a reprodutibilidade e a singularidade na criação/reprodução de modelos de espetáculos cênicos, tive de me orientar para um objeto "mais literário", porém não menos performativo.

Em Curitiba, diferentemente do que ocorre no Rio de Janeiro e em São Paulo, o exercício de crítica teatral jornalística nunca foi uma realidade estável. Entretanto, à diminuição acentuada do pouco que havia de crítica jornalística ao longo dos anos 2000 em diante, contrapôs-se o crescimento de uma massa textual observada nos programas de teatro da cidade, sobretudo no tocante à produção cênica dos novos grupos com um viés mais contemporâneo. Esse desejo de expressão, percebido por mim nos agentes criativos e 
grupos teatrais locais, atraiu, ao mesmo tempo em que estimulou, meu olhar para os programas de teatro de uma maneira mais ampla pelo Brasil afora.

A complexidade da obra cênica na contemporaneidade, juntamente com a necessidade de os agentes criativos redigirem projetos culturais endereçados às diferentes instituições de fomento, acarretou a fabricação de uma discursividade outrora inexistente. Esse conjunto de discursos de teor estético, político e programático almejava alcançar um edital para viabilização do espetáculo em si. Para que isso acontecesse, o projeto comunicava os interesses estéticos do grupo, a relevância da obra e informava ainda sobre as famigeradas contrapartidas sociais exigidas por alguns editais. Esse discurso sobre a obra, com todas as suas variantes possíveis, acabou por ser direcionado aos projetos editoriais dos programas de teatro. Nesse caso, numa versão mais leve na intenção de compartilhar com o público (muitas vezes um grupo de espectadores seguidores de certos grupos teatrais) fatos e pressupostos sobre o processo que ganhava então a forma de espetáculo. $\mathrm{O}$ fato de muitos grupos e companhias adotarem processos criativos distintos do que, no passado, fora simplesmente ensaiar uma peça (estou simplificando bastante as coisas para não me alongar) fez com que houvesse uma proliferação de argumentações sobre a poiesis da obra em gestação. O advento de elementos da performance no interior de uma encenação, bem como a adoção de uma dramaturgia performativa, que se tece sobre o palco diretamente, sem passar pelo refúgio do papel, como uma peça convencional, fizeram com que os agentes criativos tivessem que descrever suas escrituras cênicas. Isto é, traduzir seus procedimentos criativos e suas intenções políticas e estéticas na tentativa de explicitar suas metas referentes à poética do espetáculo.

Assim, passei a observar com mais cuidado os programas de espetáculos brasileiros produzidos ao longo das décadas precedentes. Observei de forma retroativa, juntamente com Felipe Matheus Bachmann (naquela altura, bolsista de iniciação científica), a produção editorial de nossos programas, sobretudo referente às duas principais praças do comércio teatral, São Paulo e Rio de Janeiro. O que notamos foi que quanto mais recuávamos no tempo, mais os programas eram padronizados e relativamente similares. Observou-se uma regularidade nas décadas precedentes referente ao número de páginas, aos cortes, aos formatos tipográficos, ao uso de cores e seleção de 
conteúdos, à distribuição dos conteúdos nas páginas dos programas, à exibição de anúncios publicitários ${ }^{1} \ldots$

Para entender plenamente a pertinência e o lugar ocupado pelo programa de teatro no interior do lazer e das instâncias de sociabilidade da sociedade letrada brasileira, seria necessário se encaminhar para uma história cultural da imprensa e da publicação desde o Brasil Colônia, ou ainda, desde quando os serviços de tipografia passaram a ser exercidos de forma regulada pela implantação da Imprensa Régia.

Entretanto, sem me deter em aspectos históricos acerca dos atrasos da implantação entre nós de serviços tipográficos, orientei-me para uma atitude comparativa, que foi a de cotejar os programas brasileiros, mormente aqueles das décadas de 1920-1950, com os programas estadunidenses e europeus, preferencialmente franceses, no mesmo período. Dessa comparação surgiram inúmeras questões e dúvidas, dentre as quais o interesse em saber sobre a origem do programa de teatro.

$\mathrm{Na}$ busca por essa origem foi que formulei a hipótese de que os programas como são hoje adviriam do resultado de uma lenta síntese entre os cartazes, os jornais-programas e os almanaques. Essas publicações se dispuseram como matrizes dentro da indústria tipográfica, forjando o programa tal como o utilizamos hoje. Volto sobre este ponto mais abaixo.

\section{Onde estão os programas?}

Os programas estão prioritariamente nos centros de documentação, nas bibliotecas, nos arquivos especializados e nas coleções particulares de pessoas, instituições, grupos e/ou companhias teatrais. Muitas vezes as coleções pessoais acabam por alimentar os acervos de bibliotecas e dos próprios centros de documentação. Há muitas listas e imagens de programas disponibilizados hoje na internet, nos portais de instituições nacionais ou estrangeiras que zelam pela preservação da documentação sobre a memória do teatro².

1 RIBEIRO, F. M. B.; TORRES NETO, W. L. O programa de teatro: um novo pacto estético cultural? In: COLÓQUIO INTERNACIONAL DE ESTUDOS LINGUÍSTICOS E LITERÁRIOS, 1., 2010, Maringá. Anais... Maringá: Universidade Estadual de Maringá, jun. 2010.

2 Foram feitas consultas nos seguintes centros de documentação: o Centro de Documentação da Fundação Nacional de Artes (Funarte), a Biblioteca Pública da Universidade 
Vou relatar aqui o que venho percebendo ao longo da investigação em torno dos programas. Durante dez meses, graças a um estágio pós-doutoral, pude manipular muitos programas de diferentes formatos, séculos e origens, em diferentes instituições, no Brasil, nos Estados Unidos e na França, além de visitar virtualmente muitos acervos por meio da internet.

Um primeiro aspecto que chamou minha atenção, durante as consultas presenciais aos acervos, foi a forma do arquivamento dos programas, em geral associados a denominações como scrapbooks, miscelâneas, memorabilias ou ephemeras. Isso não se nota com muita clareza quando se pesquisa pela internet, numa visita digital às fontes. Ou seja, havia programas de espetáculos sob essas quatro denominações dentro de uma mesma biblioteca, por exemplo.

Os scrapbooks teatrais são constituídos por meio de uma colagem de diversos itens: bilhetes, fotos, estampas, cromos, rótulos, marcadores de livro, críticas, cartões, souvenires com diversas características e formatos... Essa modalidade parte de um princípio associativo subjetivo. O leitor-espectador agrupa e cola num caderno aquilo que ele próprio seleciona, segundo seu gosto ou seu desejo de guardar e lembrar, o que é quase sempre o reflexo recíproco do gosto pela lembrança. Essa colagem de extensão variável constitui uma espécie de memória pessoal do próprio espectador (atenção aqui, pois há falsos scrapbooks). Assim, essa colagem pode oferecer farto subsídio para o conhecimento dos traços de gosto do autor do scrapbook.

Já as miscelâneas são compostas por documentos avulsos, lacunares, cuja diversidade é complexa, e não foram organizadas, necessariamente, por um espectador. Essas coleções agregam documentos atinentes à produção de um ou vários espetáculos, de grupos ou companhias, não se tratando aqui da presença de cópias de textos teatrais, mas sim de itens às vezes disparatados, frutos das montagens e das atividades de produções, como folhetos,

Federal do Estado do Rio de Janeiro (Unirio), a Biblioteca Nacional do Rio de Janeiro, a Biblioteca da Escola Superior de Teatro Célia Helena, a Théatrotèque Gaston Baty da Sorbonne Nouvelle - Paris III, a Bibliothèque-Musée da Comédie Française, a Brown University Library, a Public Library for the Performing Arts, Dorothy and Lewis B. Cullman Center. Tive acesso também a várias coleções particulares de amadores ou espectadores que, como eu, guardam os programas dos espetáculos assistidos e outros que vão colecionando. É possível consultar pela internet acervos de grande relevância, como o do Victoria and Albert Museum, em Londres, com seção específica sobre programas de teatro. 
panfletos, material de tipografia relativo à divulgação, notas de compra e venda de pequenos objetos de cena e de materiais, documentos relativos às relações trabalhistas ou organizacionais da atividade teatral, como comércio ou atividade empresarial etc.

As memorabilias, por sua vez, são constituídas por uma variedade de itens documentais, até mesmo tridimensionais, incluindo-se algum material iconográfico ou impresso de acordo com seu formato, que pertencera a alguém famoso ou de reconhecimento no mundo do espetáculo (medalhas, troféus, estatuetas, distinções honoríficas...). Este é o caso do cinzeiro que encontrei certa ocasião, durante outra pesquisa, no desaparecido Museu dos Teatros no Rio de Janeiro, e que teria sido usado por Louis Jouvet na sua estada no Brasil entre 1941 e 1942. Recordo-me, ainda, do par de luvas usadas por Jean Vilar e deixadas aos cuidados do Museu do Theatro Municipal do Rio de Janeiro (TMRJ), a título de lembrança material em sinal da sua passagem, ou também dos mais diversos objetos pessoais que pertenceram a diferentes artistas brasileiros, como Apolônia Pinto, Leopoldo Fróes e Procópio Ferreira. Esses conjuntos de objetos de coleção não são mais do que sinais materiais do efêmero da vida artística no teatro. Por vezes agregavam cartazes, programas, filipetas, todo tipo de volantes, prospectos ou folhetos relativos aos espetáculos. Dessa forma, esses documentos passam a ser denominados também como ephemeras, isto é, materiais produzidos para uma realização momentânea, os quais constituem, a posteriori, documentação relativa a um evento, ou um traço da trajetória de vida profissional de algum artista. Esse é bem o caso do programa de teatro, mas também o do cartaz, do bordereau, das cadernetas de anotação e de todo material, seriado ou não, associado à efemeridade de uma temporada teatral. Muitas vezes, ao longo da pesquisa, acabei me aproximando de hemerotecas. Havia aprendido na Biblioteca Nacional do Rio de Janeiro o que era uma, quando da minha própria iniciação cientifica, lá nos anos 1980. Apesar de a hemeroteca formar um acervo exclusivo de periódicos, é de fundamental importância para a investigação dos ditos jornais-programas ou almanaques consultar esse tipo de material, sobretudo para os jornais-programas ou gazetas, publicações relativas principalmente aos séculos XVIII e XIX. 


\section{Breve hipótese sobre a origem do programa}

Como comentei acima, minha hipótese de trabalho sobre a origem do programa de teatro no mundo do espetáculo ocidental foi estabelecida sobre a possibilidade de o programa ser o resultado de uma síntese adaptativa condicionada pelos interesses da imprensa, do comércio teatral e da publicidade na crescente indústria do entretenimento. Uma síntese de três formas de impressos: os cartazes de rua, os almanaques teatrais e os jornais-programas. Essa síntese não teve um momento inaugural. Ela não possui uma data exata que constitua o advento do programa como uma publicação autônoma. Seria, a meu ver, impossível essa precisão. Não se trata, tampouco, de uma sobreposição das propriedades comunicacionais dos impressos: CARTAZ de rua + ALMANQUE teatral ou dos teatros + JORNAL-programa = programa de espetáculo!

Essa síntese adaptativa é fruto de um movimento próprio da cultura teatral ocidental de maneira geral. Esse movimento respeita, em particular, as culturas teatrais de diferentes origens em contato com determinações materiais, como o desenvolvimento da imprensa e o papel da publicidade no interior dessas mesmas culturas. $\mathrm{O}$ que se observa é a constituição, no século XIX, de um canal comunicacional entre agentes criativos (ou agentes empresariais e produtores) e o que podemos chamar genericamente de público.

Resumindo, pode-se dizer que do cartaz, restrito pelo tempo em que anuncia uma temporada, advieram os elementos didascálicos e promocionais da obra. Do almanaque, assimilou-se um conteúdo volumoso e variável de informações diversas, fatos e efemérides que podem ser resumidos dentro da ênfase que denominei de histórica. Já nos jornais-programas, encontra-se uma massa de informação sobre as temporadas nos diversos teatros de uma cidade, o resumo de peças, a biografia de artistas, homenagens, crônicas e críticas sobre o que chamamos comumente de atualidade do movimento teatral.

O programa na atualidade, dependendo do seu projeto editorial, tem por base, mesmo que seu autor a ignore, uma similaridade com a forma e com o conteúdo veiculados por esses impressos tão consumidos nos séculos passados. 


\section{O projeto editorial de um programa}

Do ponto de vista da criação, não existe uma receita para se editar um programa de espetáculo. Em algumas culturas teatrais, essa tarefa ficava a cargo do dramaturgista. $\mathrm{O}$ que se constata hoje é uma variedade de projetos editoriais para os programas, tanto quanto são as concepções para criação de obras cênicas. Aliados a essa singularidade, deve-se acrescentar os aspectos culturais e as práticas locais no tocante ao itinerário da produção editorial num determinado continente, país, cidade e instituição teatral que promove o espetáculo. Na Alemanha, por exemplo, há programas de espetáculos, sobretudo os de ópera, que são verdadeiros livros. Eles são acompanhados de programas de mão que oferecem ao espectador a distribuição do dia para a exibição numa sessão específica. Por outro lado, quando se estudam os programas, é necessário dedicar um tempo a pensar sobre a sua autoria. Quem é o autor do projeto editorial de um programa? Existiria uma instância autoral que conceberia e determinaria o seu conteúdo e a sua forma? Não estou falando do design ou do web-design que oferece uma formatação criativa e visualmente atraente. Na contemporaneidade, pode-se estimar que o programa é uma publicação de caráter coletivo, mas que deve possuir, na origem da organização do seu discurso, uma voz autoral que encaminha o nosso olhar de leitor-espectador, visto que o programa não deixa de ser um discurso sobre a obra.

\section{O programa é uma prática discursiva}

O homem é um animal narrativo. Stanislávski, pioneiro na implantação de uma nova consciência sobre o teatro, por sua vez, na mesma época que Freud, organizou suas reflexões e procedimentos técnicos sobre o trabalho criativo do ator por meio de uma narrativa dialógica entre mestre e discípulo. No campo da teoria literária, o estruturalismo, bem como outras correntes filosóficas, não deixou de se interrogar sobre a natureza da narrativa.

Sendo a narrativa inerente ao gênero humano, resta-nos estudar as formas e os modos de operar dessa narratividade ou, por exemplo, como ela aflora nos programas. Narrar e contar fazem parte da dinâmica comunicacional 
dos agentes criativos, mesmo em tempos pós-dramáticos ou em tempos refratários à narrativa e mais dedicados ao performativo. A ênfase performativa da dramaturgia não impede os agentes criativos contemporâneos de verterem para o papel um segundo discurso, sobre a origem da obra, por exemplo, ou sobre as etapas do processo criativo ou constitutivo da obra cênica, como já disse anteriormente.

O artista na atualidade, como um agente criativo que narra independentemente da estética adotada sobre a cena, narra até sua autobiografia, correndo o risco do solipsismo com seu biodrama. O programa de teatro torna-se, assim, o meio que, para além da cena ou do projeto de encenação, acolhe e divulga a expressão de uma outra narrativa, trans-subjetiva. O programa é o documento que estabelece uma narrativa que sugere estratégias discursivas.

Podemos considerar o programa de teatro tal como Foucault (2004) assevera em A Arqueologia do saber sobre o documento que

não é mais para história, essa matéria inerte através da qual ela tenta reconstituir o que os homens fizeram ou disseram, o que é passado e o que deixa apenas rastros: ela [a história] procura definir, no próprio tecido documental, unidades, conjuntos, séries, relações. (p. 7)

Tentei observar as relações possíveis no interior dessa discursividade presente nos programas e, estabelecendo algumas ênfases, acabei tensionando as relações entre as diversas possibilidades de um projeto editorial para um programa de espetáculo.

\section{As ênfases discursivas dos programas}

Nomeei quatro ênfases discursivas que podem ser muito bem verificadas nos programas de teatro brasileiro desde o último quartel do século XIX até os dias que correm, sendo resumidas da seguinte forma: didascálica, a ênfase que se apropria dos elementos didascálicos do texto teatral, assim como o cartaz o fizera anteriormente; a ênfase histórica, que assimila os conteúdos históricos advindos, por exemplo, de publicações do tipo almanaque, que vão colaborar para a "legitimação" da obra; a ênfase estética, que se estabelece como a expressão de conteúdos que afirmam a necessária singularidade da 
obra cênica, corrente percebida desde a virada do século XIX para o XX, com o advento da moderna encenação teatral; e a ênfase genética, essencialmente contemporânea, espraiando-se desde o pós-guerra até nossos dias, que se dedica apresentar a gênese da obra cênica. Essas ênfases redacionais ou narrativas não são excludentes. Elas coabitam no interior dos mais diversos projetos editoriais para os programas.

O trajeto da descoberta da presença dessas quatro ênfases, as quais já apresentei detalhadamente noutras ocasiões ${ }^{3}$, e a hipótese sobre a gênese em si do programa se deram devido à leitura de vários trabalhos. Algumas obras e estudos pontuais foram chaves, pois abriram caminhos para minha metodologia de trabalho. Destaco aqui dois estudos teóricos incontornáveis, intitulados Palimpsestes e Seuils, de Gerard Genette (1982, 1987); dois artigos de Gilbert David $(2002,2003)$ que analisam pontualmente os programas quebequenses; e um ensaio de Umberto Eco (2010) cuja análise e interpretação sobre a função poética das listas em narrativas literárias e na pintura me ajudaram bastante. Sou grato a essas obras e autores que aparelharam meu olhar para essa chuva de programas.

Ao longo de minhas ponderações sobre a intencionalidade das redações dos programas, procurei me esquivar da pergunta: a encenação é fiel ao que promete no programa? Eu diria hoje, passado algum tempo, que sim e não. Talvez o programa não deva ser percebido, nesse caso, como uma fórmula enunciativa de aspectos da encenação ou da performance contemporânea. $O$ programa, sobretudo no contexto da produção atual, no âmbito de um teatro de linguagem ou experimental, é mais uma declaração de intenções que problematiza suas questões e menos uma promessa ou contrato a ser honrado entre palco e plateia. No plano de um teatro comercial do gênero Broadway, sim, é necessário que isso funcione como um contrato exato, até porque, em termos estéticos, voltamos para um perfil de cena modelar resultante de um trabalho teatral vizinho ao do incontornável ensaiador dramático.

3 TORRES NETO, W. L. Decifrando o espetáculo: os programas de teatro na cena contemporânea. Plural Pluriel, [S.I.], n. 14, out. 2016. Disponível em: <https://goo.gl/RGbShz>. Acesso em: 6 nov. 2017. TORRES NETO, W. L. Ensaios de cultura teatral. Jundiaí: Paco Editorial, 2016. TORRES NETO, W. L. Programa de teatro como documento: questões históricas e metodológicas. ArtCultura, Uberlândia, v. 15, n. 26, p. 205-219, jan./jun. 2013. TORRES NETO, W. L. Programas de teatro: objeto da cultura e da prática teatral. Revista Cena, Porto Alegre, n. 16, p. 1-11, 2014. 


\section{Mostre-me os seus programas, e direi o espectador que você é...}

Ao iniciar essa pesquisa, não tinha como escopo me deter em aspectos relacionados à recepção teatral. Como disse anteriormente, o meu interesse inicial era e é a gênese dessa pequena publicação - o programa - e o discurso dos agentes criativos sobre suas obras ali apresentadas: como pensam seu ofício, como concebem suas obras, como se expressam, como se dirigem ao espectador-leitor do programa. O conteúdo e a forma desse discurso foram os elementos que suscitaram minha atenção como pesquisador. Mas não pude deixar de perceber, ao longo da pesquisa, o potencial que os estudos acerca dos programas de espetáculos cênicos guardam em relação à recepção das obras teatrais. Talvez não tenha me detido nesse aspecto devido a um trauma pessoal.

Era eu um jovem estudante de artes cênicas nos anos 1980, deambulando pelo centro da cidade do Rio de Janeiro, visitando sebos e livrarias como a já extinta Livraria Brasileira, dirigida pelo senhor Osmar no Edifício Central, defronte do Teatro Glauce Rocha. Nesse entra e sai de sebos, eu procurava (hoje me dou conta disso) traços sobre a origem. Procurava vestígios de uma origem... a do nosso teatro, sobretudo aquele de perfil eurocêntrico. Como se aquele ambiente dos sebos, comportando velhos livros, antigas edições, algumas encadernadas em couro desbotado, pudesse abrigar uma obra que indicasse uma origem do teatro brasileiro, visto sempre do ponto de vista de certa importação de valores, primeiro via Portugal, depois via França - pois essa fora a lição ensinada ao estudante.

Numa dessas passagens por um antigo sebo, que se situava num sobrado defronte do Palácio do Catete, tropecei numa enorme caixa. Na verdade eram duas, mas pouco importa a quantidade hoje. $O$ fato é que as caixas estavam forradas de programas de teatro. No interior delas, me lembro com clareza cristalina, havia várias brochuras referentes a espetáculos no Teatro Municipal do Rio de Janeiro, Teatro Mesbla, Teatro Serrador, Teatro Rival e demais teatros do Rio de Janeiro e alguns também de São Paulo. E o mais surpreendente para mim: os programas traziam diversas inscrições manuscritas. Os programas estavam anotados! Como partituras musicais, pois essa 
foi a primeira percepção de quem passeia os olhos entre o alto das estantes e o baixo do chão, de caixas empilhadas. Não anotados como anotamos um livro, sublinhando aqui e acolá - os programas estavam comentados. Alguns com caneta azul, outros com caneta vermelha e alguns continham anotações a lápis. Dei uma folheada discreta no lote. Aquilo, certamente, teria vindo (não deduzi na ocasião, mas poderia ter pertencido até a um crítico) da residência de algum ex-espectador recentemente falecido, cuja família se desfizera dos seus entulhos e das suas tantas papeladas, que o ente querido teria acumulado ao longo da sua vida de frequentador de teatro. Clássico! Nós, eu e você, como o espectador falecido, possuímos uma vida misteriosa como assistentes do palco, acompanhadores deste. A vida de espectador tem validade e está associada à duração estabelecida entre ele e as obras. Enquanto o espectador continuar em sintonia com os códigos e convenções estéticas destas, a validade mantém seu prazo em dia.

Não soube ler naquele instante o sinal do destino. Também não saberia o que fazer com aquele acervo. Minha preocupação, naquele momento, era com a minha formação, que pressupunha "aprender a fazer teatro", e não aprender a refletir sobre como um possível espectador reagiria em relação à sua experiência estética, mediada por um programa de teatro.

Tratava-se, tenho clareza hoje, de um assunto para os estudos da marginalia, que nos levariam a uma reflexão sobre a recepção teatral. A caligrafia do ex-proprietário do programa, no branco das margens ou nos interstícios deixados em branco pelo projeto editorial, revelaria um potencial a ser explorado. Por conta dessa lembrança, diante desse pequeno tesouro que me assombra ainda hoje, é que talvez eu tenha sido, num primeiro instante, refratário em relação a uma atitude investigativa sobre os processos de recepção por meio da mediação do programa de teatro.

De toda forma, desde que iniciei esta pesquisa percebi o potencial presente para um estudo pormenorizado sobre a recepção teatral por meio dos programas de teatro. Neste sentido, permito-me narrar um segundo episódio, envolvendo agora o meu supervisor norte-americano no estágio pós-doutoral, que, muito gentilmente, permitiu-me dar uma olhada numa das joias da sua coleção particular. 
Explicando-Ihe meu interesse pelos programas e narrando-Ihe as novidades que havia encontrado na Library for the Performing Arts, no Lincoln Center, ele "pescou" do meio da gaveta arquivo um exemplar, cuja raridade não pôde deixar de me surpreender.

Marvin Carlson apresentou-me uma pequena relíquia de seu acervo. Puxado ao acaso do seu arquivo pessoal? Presumo que não. Era a exibição de uma preciosidade teatral, de uma figurinha das mais difíceis de se encontrar. Tratava-se de um program-souvenir da histórica montagem americana (que na verdade fora uma remontagem) da encenação do The Miracle, criado por Max Reinhardt e que estreou em 9 de dezembro de 1924, em Nova lorque, no The Century Theatre, numa versão com cenários e figurinos desenhados por Nornan-Bel Geddes, que ainda adaptou e arranjou o espaço do teatro, transformando-o numa catedral gótica para a realização da montagem. Vejam quantas informações (mesmo que breves e didascálicas) numa olhadela de cinco minutos! O espetáculo aconteceu em 1924, e Marvin Carlson tem o programa certamente devido ao seu valor histórico, como um documento-fonte importante para o estudo dessa montagem em solo estadunidense. Trata-se de um exemplar raro e de colecionador, não de espectador (como ele possui tantos outros). A mediação-recepção aqui é feita pelo valor da materialidade do documento em si, que ganha a designação de histórico por força das circunstâncias em que a obra foi concebida e exibida. Nesse caso, o programa, para além de ser um objeto de coleção, tornou-se uma espécie de traço ou vestígio do que restara daquela exibição, hoje também reconhecida pelo pesquisador brasileiro como antológica e que por conhecer de ouvir dizer sobre o espetáculo confirmava, com seu interesse de investigador, o valor atribuído à encenação por meio da apreciação de seu programa, mas também por conta do discurso da própria história do teatro.

\section{Delineamentos provisórios e balanços}

Fui estimulado a fazer esta pesquisa porque percebi que é natural que o programa, tal como é hoje, mude de suporte. Esse tipo de publicação já é digital, isto é, quase interativo, como a própria internet vai incentivando. Com as novas tecnologias é natural que o cidadão-espectador-navegador disponha, 
no seu aparelho pessoal de comunicação, do programa do espetáculo com relativa antecedência em relação à sua ida ao teatro. Ele pode visualizar uma série de informações sobre o espetáculo, jamais pensadas anteriormente, que o preparam para sua ida ao espetáculo; ou informações prosaicas que definem a sua escolha de assistir a uma ou outra obra.

Os programas em papel vão desaparecer? É a pergunta que sempre me fazem. Sim e não. Sobre o teatro já foi vaticinado o seu desaparecimento muitas vezes e nem por isso desapareceu completamente. Convenhamos que o teatro muda de aparência. E muda muito mais intensa e rapidamente no interior das culturas teatrais que não desfrutam de uma espécie de resíduo tradicional, assegurado pelo abrigo de instituições teatrais de vida longeva, estando sujeitas, essas mesmas culturas, à assimilação vertiginosa de modismos e tendências estéticas de importação, sobretudo em tempos globalizados.

Com os programas acontece o mesmo: não vão desaparecer completamente em papel de hoje para amanhã, mas vão cada vez mais ficar escassos e mudar de arranjo em seus projetos editoriais, explorando as novas plataformas digitais na tentativa de integrar obra, crítica e público. Por isso, não descarte os seus programas! Guarde-os ou doe para um acervo.

Ao ler Carvalho (2009), pude verificar que os programas de teatro, mas não somente eles, incluindo-se aí os mais diversos itens dos acervos em suporte de papel - fotografias, recortes de jornais, cadernos de direção, planos de iluminação, seus respectivos mapas de operação de luzes, croquis com esboços para cenários, figurinos e dispositivos cênicos, correspondências entre agentes criativos, materiais de divulgação e publicidade, clipagens, críticas, manuscritos, iconografias -, essa massa de materiais fabricada por agentes criativos e produtores de espetáculos é que deveria ser o objeto de progressivo estreitamento de nossos acervos com a área das humanidades digitais ou tecnológicas.

Uma área tão interdisciplinar e híbrida quanto a nossa, visto que a atividade teatral por si só é absolutamente inclusiva (diferente da música e das artes plásticas), poderia estreitar sua relação com as humanidades digitais facilmente. As artes cênicas são as artes mais participativas, insisto, já conhecendo e dominando processos e dinâmicas interdisciplinares de forma integrada há muitos anos, congregando diversos saberes e especialidades 
profissionais. Nesse sentido, destacaria os programas de teatro, que serviriam de ponto de partida, de protótipo ou de projeto piloto para a inserção das artes cênicas nas humanidades digitais, com a criação de um vasto repositório digital desses documentos. Isto é, a formação de bases de dados: bancos de imagens constituídos por programas já classificados, oriundos dos distintos acervos das instituições brasileiras responsáveis pela preservação das artes cênicas no Brasil.

\section{Referências bibliográficas}

CARVALHO, M. D. A Constituição de coleções especializadas em artes cênicas: do imaterial ao documental. 2009. 160 f. Dissertação (Mestrado em Cultura e Informação) - Escola de Comunicações e Artes, Universidade de São Paulo, São Paulo, 2009.

DAVID, G. Éléments d'analyse du paratexte théâtral: le cas du programme de théâtre. L'Annuaire Théâtral - Revue Québécoise d'études Théatrales, Montréal, n. 34, p. 96-111, automne 2003.

Théâtres au programme: panorama des programmes de théâtre de langue française à Montréal au XXe siècle. Montréal: Bibliothèque Nationale du Québec; CÉTUQ, 2002.

ECO, U. A vertigem das listas. Tradução Eliana Aguiar. Rio de Janeiro: Record, 2010.

FOUCAULT, M. A arqueologia do saber. Tradução Luiz Felipe Baeta Neves. 7. ed.

Rio de Janeiro: Forense Universitária, 2004.

GENETTE, G. Palimpsestes: la littérature au second degré. Paris: Éditions du Seuil, 1982.

Seuils. Paris: Éditions du Seuil, 1987.

Recebido em 02/10/2017

Aprovado em 21/10/2017

Publicado em 26/12/2017 